\title{
Correlação entre cortisol e testosterona em touros atletas submetidos a treinamento
}

Correlation of cortisol and testosterone in athlete bulls submitted to training

\author{
Michelle Marangoni Paixão1, Gabriel Mazi Zanini' ${ }^{1}$, André Silva Ananias ${ }^{1}$, Sofia Botsaris \\ Delchiaro $^{3 *}$, Halim Atique Netto ${ }^{2}$, Suellen Miguez González ${ }^{3}$ \\ ${ }^{1}$ Médico Veterinário Autônomo \\ ${ }^{2}$ Centro Universitário de Rio Preto (UNIRP), São José do Rio Preto, SP, Brasil \\ ${ }^{3}$ Universidade Estadual de Londrina (UEL), Londrina, PR, Brasil
}

\section{Resumo}

Touros em treinamento $(\mathrm{n}=17)$ para rodeio foram avaliados quanto a interferência do estresse na produção de testosterona. Foi realizada análise de parâmetros quanto a higidez dos touros antes do treinamento e coleta de sangue. Após o treinamento, foi realizada a segunda coleta de sangue. As amostras coletadas antes do treinamento foram submetidas à mensuração dos hormônios cortisol e testosterona e as amostras após o treinamento apenas à dosagem de cortisol. Iniciou-se uma nova sequência de coleta para dosar e avaliar a testosterona. Ambos os hormônios foram mensurados pelo método de radioimunoensaio. A análise estatística para comparação de cortisol e testosterona, assim como para o perímetro escrotal e testosterona foi realizada através da comparação de Person, com nível de 5\% de significância, através do Action 3.1 versão R 3.0.2 (Campinas, SP, Brasil). A dosagem de cortisol sérica antes e após o treinamento resultou em correlação positiva $(0,071)$, demonstrando diferença estatística $(\mathrm{p}=0,0004)$ nesses dois momentos avaliados. A comparação entre a testosterona do primeiro dia e o cortisol antes do treinamento foi negativa assim como a testosterona do segundo dia com o cortisol após treinamento. Conclui-se que houve evidência de estresse após o treinamento sem interferência na produção de testosterona.

Palavras-Chave: Bovino, montaria, estresse, rodeio, reprodução.

\begin{abstract}
Bulls in training $(n=17)$ for rodeo were evaluated for stress interference in testosterone production. Parameter analysis was performed regarding the health of the bulls before training and blood collection. After the exercise, the second blood collection was performed. The samples collected before the training were submitted to the measurement of cortisol and testosterone hormones and the samples after the training only to the cortisol dosage. A new collection sequence was started for dosing and evaluating testosterone. Both hormones were measured by the radioimmunoassay method. The statistical analysis for comparison of cortisol and testosterone, as well as for the scrotal perimeter and testosterone was performed by Pearson correlation with a 5\% level of significance through Action 3.1 version R 3.0.2 (Campinas, SP, Brazil). Serum cortisol dosage before and after training resulted in a positive correlation (0.071), showing statistical difference $(p=0.0004)$ in these two moments evaluated. The comparison between first day testosterone and cortisol before training was negative as was testosterone on the second day with cortisol after training. It was concluded that there was evidence of post-training stress without interference in the production of testosterone.
\end{abstract}

Keywords: Bovine, mount, stress, rodeo, reproduction.

\section{Introdução}

O rodeio consiste em um esporte onde um peão realiza a tentativa de permanecer por oito segundos em cima de um animal e, após esse período, recebe uma avalição quanto à performance. Essa modalidade ocorre em vários países, onde podemos incluir o Brasil (Goldhawk, 2016).

A grande preocupação com os animais de rodeio é quanto o seu bem-estar, esta questão é muito discutida e alguns fatores são apontados como pontos críticos destes debates, como exemplo pode-se citar 
Paixão et al. Correlação entre cortisol e testosterona em touros atletas submetidos a treinamento.

o comportamento agressivo que os animais apresentam a exposição a dor, angústia e medo (Goldhawk, 2016).

O fator temperamento desses animais e o sistema endócrino dos mesmos propiciam o estímulo para os pulos. Estes são totalmente influenciados pelos hormônios cortisol e testosterona (Geburt et al., 2015). Através de alguma situação estressante, no caso o ato de pular devido a presença de um robô ou peão no dorso do touro, ocorre a liberação de catecolaminas e liberação hipotalâmica de hormônios liberadores de corticotrofina $(\mathrm{CRH})$ sérica. Após alguns segundos a hipófise anterior libera ACTH (adrenocorticotrófico) que realiza o estímulo do córtex adrenal a secretar cortisol (Stahringer et al., 1990; Curley et al., 2008; Burdick et al., 2010). Já a testosterona poderá propiciar uma agressividade espontânea no animal (Geburt et al., 2015).

Cientificamente é comprovado que a liberação sérica de cortisol inibe a produção de testosterona, entretanto não se conhece até o momento o quanto essa inibição interfere no rendimento de pulo do animal (Lockwood et al., 2016).

Portanto, objetiva-se: i) correlacionar a dosagem de cortisol e testosterona antes e após a montaria; ii) avaliar o estresse antes e após a montaria; iii) determinar padrões de frequência cardíaca e respiratória antes e após a montaria de touros atletas.

\section{Material e Métodos}

Touros em treinamento $(\mathrm{n}=17)$, mestiços, com peso médio $450 \mathrm{Kg}$ e com escore de condição corporal de 2-3 (1-5) foram avaliados quanto a interferência do estresse na produção de testosterona. O experimento foi realizado em uma propriedade localizada na cidade de Icém-SP destinada na criação de touros atletas de rodeio. Durante o período de execução do experimento a temperatura endorretal dos touros variou de 32 a $36^{\circ} \mathrm{C}$.

O treinamento desses machos ocorre uma vez por semana com intuito de proporcionar condicionamento e performance ideal, de forma que possibilite a participação em rodeios como atletas da modalidade conhecida como Montaria em Touros ou Bullriding.

Todos os touros antes do treinamento foram conduzidos ao brete de contenção para análise de parâmetros quanto a higidez e não foi encontrado nada digno de nota quando se aferiu a temperatura endorretal, frequência cardíaca, frequência respiratória e movimentos ruminais. Também foi feita a coleta de sangue da veia caudal com agulha $1,2 \mathrm{~mm}$ x $40 \mathrm{~mm}$ e tubo convencional sem anticoagulante de $5 \mathrm{ml}$ devidamente identificado. Após a coleta de sangue, os tubos foram centrifugados para obtenção do soro, os quais foram armazenados e congelados em freezer para envio ao laboratório para a dosagem de cortisol e testosterona de cada animal. Esses animais permaneceram em repouso, sem estímulo estressante a fim de comparar os resultados antes e após o treinamento.

Nesse momento, avaliou-se também parâmetros indicadores de estresse, como a frequência cardíaca e respiratória dos animais. Para que fosse possível realizar uma comparação entre o nível de estresse aparente basal e o nível de estresse aparente após o exercício, um técnico capacitado e previamente treinado, estimou esse elemento com os animais em repouso pelo método descrito por Rueda et al. (2015), no qual a pontuação varia de 1 à 5, sendo: 1 = Nenhum movimento do corpo e cabeça, cauda e orelhas relaxadas; 2 = Movimentos inquietos e cabeça, orelha e cauda erguidas; 3 = Frequentes movimentos de cabeça, orelha, cauda e membros, porém não vigorosos, com vocalização e esclera podendo ser visível; 4 = Constantes movimentos abruptos e vigorosos do corpo inteiro, vocalização, esclera visível, respiração audível, podendo saltar ou cair; $5=$ Esclera aparente e reação de "congelamento".

Analisou-se também, o tempo de saída do brete (adaptado de Burrow et al., 1988), no qual um avaliador treinado com cronômetro, iniciou a contagem a partir da passagem da cabeça do touro pelo final do brete e finalizou após a passagem da cabeça do animal em uma marcação realizada dois metros à frente.

Nessa etapa, foi mensurada a circunferência escrotal de cada animal para que, posteriormente, fosse feita a correlação entre esse parâmetro e a produção de testosterona. Os touros também foram inspecionados quanto à presença de ectoparasitas (moscas e carrapatos), com intuito de investigar a influência em relação ao bem-estar e nível de agitação desses. Considerou-se machos com nenhum ectoparasita visível, com menos de 50 ectoparasitas visíveis e touros com mais de 50.

Após a saída do brete de contenção, os referidos animais foram encaminhados à arena com o propósito de serem analisados durante um teste, no qual um juiz tecnicamente capacitado deu notas individuais avaliando a performance atlética de cada touro, de acordo com a modalidade. Para isso, 
utilizou-se um dispositivo chamado Dummy, conhecido como "robô cowboy", que simula o efeito da monta pelo peão (Fig. 1). A avaliação realizada pelo juiz inicia-se a partir do momento em que se abre a porteira do brete até a desativação automática do Dummy após oito segundos. Esta é fundamentada nos critérios de avaliação da propriedade em questão utilizada na prova de performance de touros de rodeio. Os animais foram analisados apenas uma vez e o exercício praticado teve um nível médio a alto de intensidade.
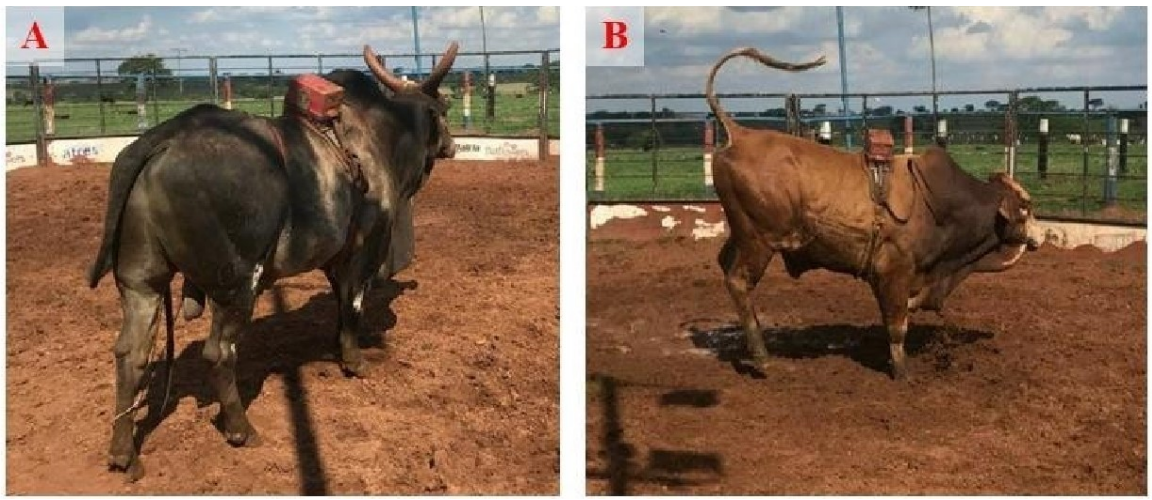

Figura 1 A e B. Touros de rodeio com o robô cowboy Dummy utilizado para mimetizar o possível estresse ocasionado pelo rodeio.

Ao final de cada julgamento, cada touro recebeu uma nota de acordo com o desempenho atlético que é avaliado pelo grau de dificuldade que o touro oferece durante os pulos. Outra pontuação foi dada pelo nível de agressividade demonstrado, avaliando se os animais estavam inquietos e agitados ou tentavam pular, deitar ou virar dentro do brete, sendo de 1 a 5, onde o 1 representa o animal que demonstrou menos agressividade e o 5 o touro que demonstrou mais agressividade durante a permanência no brete.

Após a avaliação, o touro foi direcionado, imediatamente ao brete de contenção para a segunda coleta de sangue, realizada de acordo com a metodologia supracitada. Nesse período, os bovinos foram submetidos a auscultação cardíaca, respiratória e avaliação quanto ao nível aparente de estresse.

As amostras foram centrifugadas para a obtenção do soro a partir do sangue total e enviadas devidamente acondicionadas para o Laboratório de Endocrinologia da Universidade Estadual Paulista "Júlio de Mesquita Filho", Campus de Araçatuba. As amostras coletadas antes do treinamento foram submetidas à mensuração dos hormônios cortisol e testosterona e as amostras coletadas após o treinamento apenas à dosagem de cortisol, já que o pico sérico desse hormônio se dá em menor tempo que o de esteróides, permitindo assim a detecção de elevações de concentração em poucos minutos.

Após 24 horas da coleta de testosterona realizada antes do treinamento, denominada D1, iniciouse uma nova sequência de coleta, D2, para dosar e avaliar a testosterona novamente, já que esse hormônio só tem alteração sérica após 12-24 horas. Ambos os hormônios foram mensurados pelo método de Radioimunoensaio (RIA; Fig. 2).
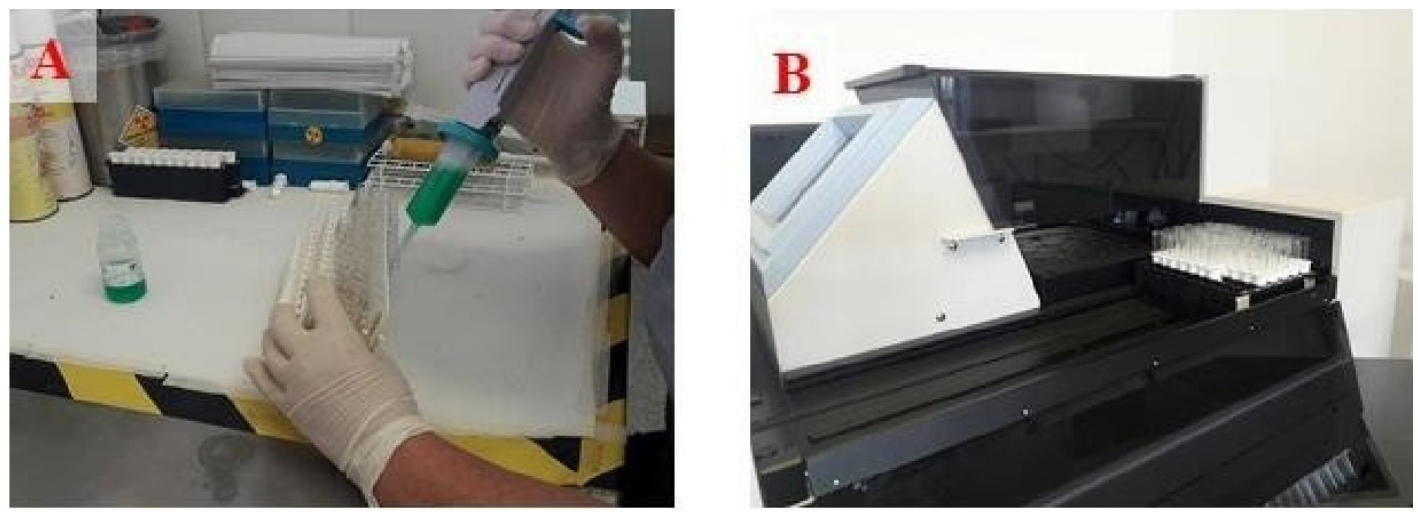

Figura 2. A e B. Processamento das amostras sanguíneas pelo método Radioimunoensaio. 
Paixão et al. Correlação entre cortisol e testosterona em touros atletas submetidos a treinamento.

\section{Análise Estatística}

A análise estatística para correlação entre as dosagens de cortisol e testosterona, assim como para o perímetro escrotal e testosterona foi realizada através da correlação de Person, com nível de 5\% de significância. O programa estatístico utilizado foi Action 3.1 versão do R 3.0.2 (Campinas, SP, Brasil).

\section{Resultados}

A dosagem de cortisol sérica antes e após o treinamento foi comparada, resultando em uma correlação positiva $(0,774)$ entre tais variáveis, demonstrando diferença estatística $(p=0,0004)$ entre os valores obtidos nesses dois momentos avaliados.

A dosagem de testosterona sérica no primeiro e segundo dia apresentou correlação positiva $(0,071)$, porém não obteve diferença estatística significativa $(p=0,784)$. A comparação entre a testosterona do primeiro dia e o cortisol antes do treinamento foi negativa $(-0,449)$. A testosterona do segundo dia com o cortisol após treinamento também obteve correlação negativa $(-0,531)$. Assim, não houve correlação positiva entre os hormônios supracitados. A tabela 1 demonstra os valores da correlação de cortisol (antes e depois do treinamento) e testosterona nos dois momentos em que foi dosada.

Tabela 1. Valores de média e desvio padrão da dosagem de cortisol (antes e depois da montaria) e testosterona no D1 e D2.

\begin{tabular}{llll}
\hline & Coleta 1 & Coleta 2 & Valor p \\
\hline Cortisol & $33,60 \pm 32,69^{\mathrm{a}}$ & $45,60 \pm 24,17^{\mathrm{b}}$ & 0.0004 \\
Testosterona & $6,93 \pm 5,00^{\mathrm{a}}$ & $9,79 \pm 7,04^{\mathrm{a}}$ & 0.784 \\
\hline
\end{tabular}

${ }^{\mathrm{ab}}$ Letras diferentes na mesma coluna indicam diferença estatística $(P<0.05)$. variação.

O coeficiente de variação da testosterona foi de $37,3 \%$, repercutindo em dados com alta

Foi feita a média da dosagem de testosterona no D1 e D2 e, posteriormente, correlacionada com o perímetro escrotal, no qual demonstrou correlação positiva (0.394) mas sem diferença estatística ( $\mathrm{p}=$ $0,130)$. Os valores da média da testosterona e perímetro escrotal estão demonstrados na tabela 2.

Tabela 2. Valores de média e desvio padrão da dosagem de testosterona e perímetro escrotal dos touros

\begin{tabular}{ll}
\hline & Média \pm DP \\
\hline Testosterona & $8,36 \pm 6,21$ \\
Perímetro escrotal & $35,61 \pm 3,69$ \\
Valor $p$ & 0,130 \\
\hline
\end{tabular}

Na tabela 3 constam os valores da média da frequência cardíaca antes da montaria, que foi de 85 bpm e depois da montaria onde obteve- se $110 \mathrm{bpm}$. Assim como a relação da frequência respiratória no primeiro momento, que foi de $42 \mathrm{mpm}$, e no segundo momento, $47 \mathrm{mpm}$.

Tabela 3. Valores de média e desvio padrão da frequência respiratória e cardíaca dos touros antes e depois da montaria

\begin{tabular}{lll}
\hline & Antes da montaria & Depois da montaria \\
\hline Frequência respiratória & $42,11 \pm 8,49^{\mathrm{a}}$ & $47,29 \pm 9,61^{\mathrm{a}}$ \\
Frequência cardíaca & $85,47 \pm 14,33^{\mathrm{a}}$ & $110,17 \pm 31,01^{\mathrm{b}}$
\end{tabular}

${ }^{\mathrm{ab}}$ Letras diferentes na mesma coluna indicam diferença estatística $(P<0.05)$.

Quanto ao escore de avaliação para a variável estresse antes e depois da montaria, este se manteve com escore 2, nos quais os animais demonstraram movimentos inquietos de cabeça, orelha e cauda.

\section{Discussão}

Sabe-se que os níveis de cortisol tendem a aumentar diante de uma situação de estresse, tornando 
o animal susceptível a depreciação do sistema imunológico. Assim o estresse estimula o eixo hipotálamopituitária-adrenal liberando catecolaminas e glicocorticoides que alteram a bioquímica sanguínea, composição celular, metabolismo energético e resposta imune (Brunel, 2018). No presente estudo, constatou-se que a dosagem de cortisol apresentou diferença significativa antes e depois do treinamento, fato este esperado devido ao esforço físico dos bovinos, uma vez que o exercício representa um estresse físico que pode alterar a homeostase (Cayado et al., 2006).

De acordo com o estudo de Cayado et al. (2006), foram colhidas amostras de sangue de cavalos divididos em um grupo controle de animais que não eram atletas e outro grupo de animais de competição. Foi avaliado o nível de cortisol e ACTH plasmático antes e depois da performance atlética em animais com treino moderado, intermediário e mais experientes. $\mathrm{O}$ estudo demonstrou que os animais avaliados apresentaram uma resposta fisiológica clássica ao estresse e que programas de treinamento diferentes influenciam nessa resposta.

O aumento de cortisol observado nesse estudo não é crônico, uma vez que a coleta de sangue prévia a montaria indicou valores mais baixos de cortisol e pelo fato de os touros estarem condicionados a rotina de treinamentos e competições. Com relação à animais que realizam performances atléticas, Curley et al. (2006) e Cooke et al. (2009) demonstraram que o nível de cortisol se mantém naqueles que estão condicionados com a rotina de treinamentos.

Sugere-se então que o aumento do cortisol do presente estudo é físiológico, dada a atividade atlética desempenhada pelos touros. Tal fato é associado com os resultados da avaliação de estresse que se manteve na classificação 2, ou seja, os animais apresentaram agressividade baixa quando contidos dentro do brete. Estudos realizados em equinos já indicaram que os cavalos atletas submetidos a treinamentos de intensidade baixa a moderada tendem a aumentar pouco ou não terem alteração nos níveis de cortisol (Hamlin et al., 2002; Malinowsky, 2004 ).

A avaliação cardíaca e respiratória dos touros de rodeio foi semelhante nos dois momentos avaliados, com diferença discreta apenas para os padrões cardíacos. Vasconcelos et al. (2000) relataram a média de 50 e $56 \mathrm{bpm}$, respectivamente antes e após a montaria dos touros. Tais autores também descreveram a média da frequência respiratória, sendo de $35 \mathrm{mpm}$ nos dois momentos supracitados. Nosso estudo apresentou parâmetros distintos, principalmente em relação a avaliação cardíaca. As diferenças quanto a idade dos animais e a metodologia empregada dos trabalhos podem ter influenciado nos resultados. Neste estudo as instalações da propriedade proporcionaram a avaliação dos touros imediatamente após a montaria, tal fato pode ter influenciado na distinção dos resultados apresentados.

Em relação a testosterona e cortisol, comprovamos que ambos não possuem relação positiva nas avaliações propostas. A testosterona mostrou-se com coeficiente de variação alto, sugerindo que outros fatores podem estar envolvidos no declínio ou aumento desse hormônio durante o treinamento de touros de rodeio. Um estudo realizado com touros Angus, mensurou o cortisol e testosterona em dois momentos: em repouso e após excitação. Este estudo não encontrou diferença entre os níveis de cortisol e testosterona nos momentos avaliados (Lockwood et al., 2016).

Um estudo de Stradaioli et al. (2017), que comparou os níveis de cortisol e sua influência sobre as características do sêmen de touros jovens Bos taurus durante 12 meses utilizando pelo da região escapular. As amostras foram coletadas no momento da chegada dos touros na estação onde fizeram quarentena e as amostras de pelo coletadas estavam em diferentes fases fisiológicas (anagênese, catagênese e telogênese). Os resultados obtidos refletiram concentrações hormonais de pelo menos 1 mês antes do início do experimento. Consecutivas amostras de pelo continuaram sendo coletadas mensalmente até o término do experimento. Além disso, foram feitas 2 coletas de sêmen com intervalo de 30 minutos entre cada uma, uma vez por semana com vagina artificial.

Foi observado que o cortisol dos bovinos aumentou devido a quarentena e voltou a diminuir, concluindo que o aumento de cortisol não teve influência no sêmen e nem na espermatogênese (Stradaioli et al., 2017). Portanto, a intensidade do exercício é fator determinante para os parâmetros hormonais, no presente caso é notável que não houve alteração do eixo hipotálamo-hipófise-adrenal e, também, nenhuma alteração do trato reprodutivo.

No entanto, em nosso estudo com touros de rodeio, obtivemos resultados distintos, já que houve diferença entre os valores de cortisol antes e depois do treinamento. Sugerimos que a distinção dos dados entre os trabalhos apresentados se deve ao treinamento específico dos touros de rodeio, nos quais utilizamos robôs para mimetizar a montaria cronometrada em oito segundos. Assim, o tipo de estresse proporcionado nos experimentos supracitados é diferente, podendo justificar os resultados apresentados.

A correlação entre o cortisol e testosterona sérica antes e depois do treinamento de touros de rodeio são escassos. Os trabalhos que envolvem bovinos atletas se restringem ao bem-estar e afecções do 
sistema locomotor (Goldhawk et al., 2016). Os trabalhos que abordam o assunto em questão foram realizados no Estados Unidos, com padrões raciais, tipo de treinamento, alimentação, temperatura ambiente distinto. Assim, pode-se considerar este trabalho inédito, uma vez que apresenta dados de touros atletas no Brasil em condição climática diferenciadas dos Estados Unidos.

\section{Conclusão}

Os touros de rodeio apresentaram estresse após o treinamento, entretanto não houve interferência deste sobre a produção de testosterona. Os animais demonstraram ótima performance atlética, demonstrando que o treinamento não interfere na higidez dos animais e sugerindo que o aumento do cortisol é fisiológico em resposta ao exercício físico, não causando prejuízo para o touro. Assim, sugerimos que touros em treinamento podem apresentar índices reprodutivos satisfatórios para disseminar características quanto ao desempenho atlético.

\section{Referências}

Burdick NC, Carroll JA, Hulbert LE, Dailey JW, Willard ST, Vann RC, Welsh Jr TH, Randel RD. Relationships between temperament and transportation with rectal temperature and serum concentrations of cortisol and epinephrine in bulls. Livest Sci, v.129, n.1-3, p.166-172, 2010.

Burrow HM, Seifeirt GW, Cobert NJ. A new technique for measuring temperament in cattle. Proc Aust Soc Anim Prod, v.17, p.154-158, 1988.

Brunel HDSS, Dallago BS, Almeida AM, Assis AZ, Calzada RJ, Alvarenga AB, Menezes AM, Barbosa JP, Lopes PR, González FH, Mcmanus C, Broom D, Bernal FE. Hemato-biochemical profile of meat cattle submitted to different types of pre-loading handling and transport times. Int J Vet Sci Med, v.06, n.01, p.90-96, 2018.

Cayado P, Munoz-Escassi B, Dominguez C, Manley W, Olabarrl B, Sanchez De La Muelas M, Castejon F, Maranon G, Vara, E. Hormone response to training and competition in athletic horses. Equine Vet J Supplem, v.36, p.274-278, 2006.

Cooke RF, Arthington JD, Austin BR, Yelich JV. Effects of acclimation to handling on performance, reproductive, and physiological responses of Brahman-crossbred heifers. J Anim Sci, v.87, n.10, p.34033412, 2009.

Curley Jr KO, Paschal JC, Welsh Jr TH, Randel, R.D. Technical note: Exit velocity as a measure of cattle temperament is repeatable and associated with serum concentration of cortisol in Brahman bulls. J Anim Sci, v.84, n.11, p.3100-3103, 2006.

Curley Jr KO, Neuendorff DA, Lewis AW, Cleere JJ, Welsh JR TH, Randel RD. Functional characteristics of the bovine hypothalamic- pituitary-adrenal axis vary with temperament. Horm Behav, v.53, n.1, p.20-27, 2008.

Geburt K, Piechotta M, Borstel UKD, Gauly M. Influence of testosterone on the docility of German Simmental and Charolais heifers during behaviour tests. Physiol Behav, v.141, p.164-171, 2015.

Goldhawk C, Bond G, Grandin T, Pajor, E. Behaviour of bucking bulls prior to rodeo performances and relation to rodeo and human activities. Appl Anim Behav Sci, v.181, p.63-69, 2016.

Hamlin MJ, Shearman JP, Hopkins WG. Changes in physiological parameters in overtrained Standardbred racehorses. Equine Vet J, v.34, n.4, p.383-388, 2002.

Lockwood SA, Kattesh HG, Rhinehart JD, Strickland LG, Krawczel PD, Wilkerson JB, Kirkpatrick FD, Saxton AM. Relationships among temperament, acute and chronic cortisol and testosterone concentrations, and breeding soundness during performance testing of Angus bulls. Theriogenology, v.89, p.140-145, 2016.

Malinowski K. Stress Management for Equine Athletes. 2004. Disponível em https://esc.rutgers.edu/fact_sheet/stress-management-for-equine-athletes/. Acesso em 29 abr. 2019.

Rueda PM, Sant'Anna AC, Valente TS, Costa MJRP. Impact of the temperament of Nellore cows on the quality of handling and pregnancy rates in fixed-time artificial insemination, Livest Sci, v.177, p.189195,2015

Stahringer RC, Randel RD, Neuendorff DA. Effects of naloxone and animal temperament on serum luteinizing hormone and cortisol concentrations in seasonally anestrous Brahman heifers. Theriogenology, v.34, n.2, p.393- 406, 1990.

Stradaioli G, Peric T, Montillo M, Comin A, Corazzin M, Veronesi MC, Prandi A. Hair cortisol and testosterone concentrations and semen production of Bos taurus bulls. Ital J Anim Sci, v.16, n.4, p.631- 
639, 2017.

Vasconcelos OT, Alessi AC, Esper CR, Franceschini PH. Avaliação técnico-científica da utilização do sedém em bovinos de rodeio. Rev Educ Contin CRMV-SP, v.3, n.2, p.72-77, 2000. 